\title{
The Celiac Trunk and Its Anatomical Variations: A Cadaveric Study
}

\author{
David F. Pinal-Garcia ${ }^{\mathrm{a}}$, Carlos M. Nuno-Guzman ${ }^{\mathrm{a}}$, b, d, Maria E. Gonzalez-Gonzalez ${ }^{\mathrm{c}}$, \\ Tomas R. Ibarra-Hurtado ${ }^{a}$
}

\begin{abstract}
Background: The celiac artery, celiac axis or celiac trunk is the first major abdominal branch of the aorta. Anatomic variations and accessory vessels have been reported with variable percentages. The purpose of this study was to report the pattern of the celiac trunk and its anatomic variations in a sample of Mexican population.
\end{abstract}

Methods: Celiac trunk dissection was performed in 140 fresh cadavers. Cadavers of Mexican subjects aged 18 years and older were included. Cadavers with previous upper abdominal surgery, abdominal trauma, disease process that distorted the arterial anatomy or signs of putrefaction were excluded. Celiac trunk variations and external diameter, accessory vessels, and vertebral level of origin were described. Celiac trunk patterns were reported according to the Panagouli classification. This study was reviewed and approved by the Ethics Committee of our Hospital.

Results: The celiac trunk derived in a common hepatic artery, a left gastric artery and a splenic artery (type I) in $43.6 \%$ of dissections. A true tripod was found in $7.1 \%$ and a false tripod in $36.4 \%$. Celiac trunk bifurcation (type II) was found in $7.1 \%$. Additional branches (type III) were observed in $47.9 \%$. One or both phrenic arteries originated from the celiac trunk in $41.4 \%$ of dissections. Celiac trunk tetrafurcation was observed in $12.9 \%$, pentafurcation in $12.9 \%$, hexafurcation in $1.4 \%$, and heptafurcation in $0.7 \%$. The mean diameter of the celiac trunk ranged from 6 to $12 \mathrm{~mm}$, with a mean diameter of $7.2 \mathrm{~mm}$ (SD $=1.39 \mathrm{~mm})$. No significant difference was found between the diameters of the different types of celiac trunk $(\mathrm{P}>0.05)$. The celiac trunk

Manuscript submitted January 11, 2018, accepted January 26, 2018

aDepartment of General Surgery, Hospital Civil de Guadalajara "Fray Antonio Alcalde", Calle Hospital No. 278, Col. El Retiro, Sector Hidalgo, C.P. 44280, Guadalajara, Jalisco, Mexico

bDepartamento de Clinicas Quirurgicas, Centro Universitario de Ciencias de la Salud, Universidad de Guadalajara, Sierra Mojada 950, Colonia Independencia Oriente, C.P. 44340, Guadalajara, Jalisco, Mexico

'Departamento de Clinicas Medicas, Centro Universitario de Ciencias de la Salud, Universidad de Guadalajara, Sierra Mojada 950, Colonia Independencia Oriente, C.P. 44340, Guadalajara, Jalisco, Mexico

${ }^{\mathrm{d} C}$ Corresponding Author: Carlos M. Nuno-Guzman, Department of General Surgery, Hospital Civil de Guadalajara "Fray Antonio Alcalde", Calle Hospital No. 278, Col. El Retiro. Sector Hidalgo, C.P. 44280, Guadalajara, Jalisco, Mexico. Email: carlosnunoguzman@hotmail.com

doi: https://doi.org/10.14740/jocmr3356w originated between the 12th thoracic and first lumbar vertebral bodies in $90 \%$ of dissections.

Conclusions: Trifurcation of the celiac trunk was lower than previously reported. A high proportion of cases with additional vessels were found.

Keywords: Celiac trunk; Celiac artery; Celiac axis; Anatomic variations; Cadaveric study; Celiac trunk heptafurcation; Panagouli classification

\section{Introduction}

The celiac artery, celiac axis or celiac trunk is the first major abdominal branch of the aorta. The celiac trunk originates in the ventral aspect of the aorta, just after it crosses the diaphragmatic aortic hiatus, at the level of the 12th thoracic and first lumbar vertebrae and trifurcates into the common hepatic artery, left gastric artery and splenic artery [1]. This trifurcation was described by von Haller [2] and is considered the classic presentation of the celiac trunk, which is known as "tripus Halleri". It supplies irrigation to the abdominal foregut derivatives, the liver, gallbladder, pancreas and spleen. Two forms of trifurcation have been described: a "true" tripod is considered when the common hepatic artery, left gastric artery and splenic artery have a common origin, constituting a hepatogastrosplenic trunk. When one of these arteries arises before the remaining two in the course of the celiac trunk, it is called a false tripod.

Diverse classifications also include an incomplete celiac trunk due to bifurcation, while the third branch originates from a different artery, as well as a superior mesenteric artery or inferior mesenteric artery originating in combination with the previous variations, and even independent origins of the common hepatic artery, left gastric artery and splenic artery, which is known as absence of the celiac trunk [3-7]. Several types of variations and additional branches are not included in these classifications. Through a systematic review, Panagouli et al [8] proposed a new classification including all the described celiac trunk variations. Knowledge of the celiac trunk anatomic pattern is clinically relevant in esophageal, gastroduodenal, hepatic, biliary and pancreatic angiographic and surgical procedures. 
The purpose of this study was to report the pattern of the celiac trunk and its variations in a sample of Mexican population, according to the classification by Panagouli et al [8].

\section{Materials and Methods}

\section{Subjects}

Dissection of the celiac trunk was performed in 140 fresh cadavers of Mexican nationality subjects. There were 121 male $(86.4 \%)$ and 19 female cadavers $(13.6 \%)$; the mean age was 48.8 years (range: 18 - 79 years). The inclusion criteria were: cadavers of Mexican subjects aged 18 years and older. Cadavers with previous upper abdominal surgery, abdominal trauma, disease process that distorted the arterial anatomy or signs of putrefaction were excluded. This study was reviewed and approved by the Ethics Committee of our Hospital. Informed consent was not required.

\section{Cadaveric dissection method}

Once the autopsy was concluded, through the autopsy thoracoabdominal midline incision, the liver, the stomach, and pancreas were dissected and retracted. Once the common hepatic artery, the left gastric artery and the splenic artery were identified, their course was followed to their site of origin. The presence of a "true tripod" or a "false tripod" was examined. Celiac trunk variations, accessory vessels and site of origin were also recorded. Celiac trunk patterns were reported according to the Panagouli classification. The stomach, large and small bowels and the pancreas were dissected and retracted in order to expose the total length of the abdominal aorta. The vertebral level of the celiac trunk origin was determined by palpation in cephalic direction beginning from the fifth lumbar vertebral body.

\section{Arterial measurement and documentation}

Arterial external diameters were measured using a PRECISE 3" Mini Vernier Caliper - Plastic Precision: 1/128 inch or 0.05 $\mathrm{mm}$. A measuring tape was used to measure arterial lengths. Photographs of the celiac trunk and its branches were taken using a digital camera (Nikon, Model D5100. 16.2MP).

\section{Statistical analysis}

Descriptive statistics, including the mean, maximum and minimum values, and standard deviation (SD), were used to describe the continuous variables. Percentages were calculated for categorical variables. Continuous variables were assessed with the Student's $t$-test. P value $<0.05$ was considered significant. Statistical analysis was performed with the SPSS version 20 statistical software (IBM SPSS Statistics for Windows, version 20.0, IBM Corp., Armonk, NY). Data were collected and

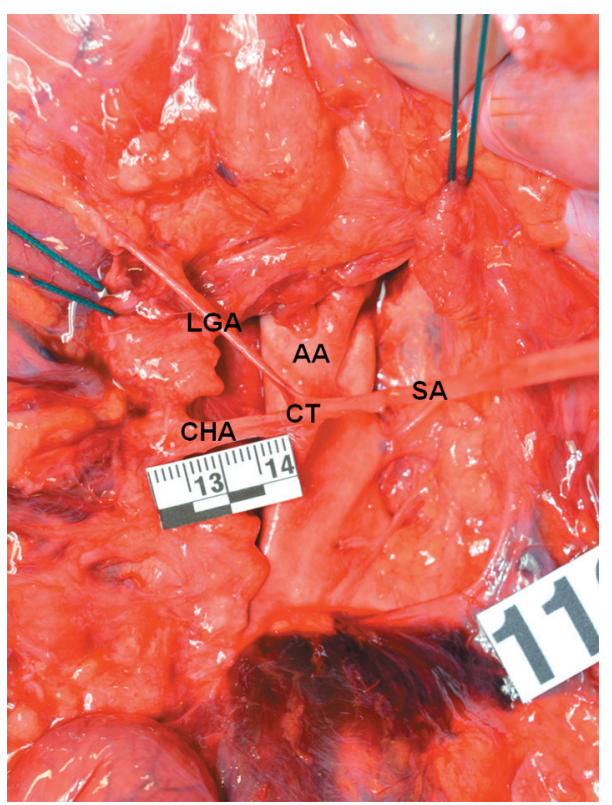

Figure 1. True tripod, "tripus Halleri". LGA, CHA and SA have a common origin (Panagouli type I, form 1). CT: celiac trunk; LGA: left gastric artery; SA: splenic artery; CHA: common hepatic artery.

analyzed using the Statistical Package for the Social Sciences (IBM SPSS Statistics for Windows, version 20.0, IBM Corp.).

\section{Results}

The celiac trunk derived in a common hepatic artery, a left gastric artery and a splenic artery (type I) in $43.6 \%$ of the cadavers (61/140). Trifurcation of the celiac trunk into the common hepatic artery, the left gastric artery and the splenic artery ("true tripod" or tripus Halleri) was found in $7.1 \%$ of dissections (10/140) (Fig. 1). The celiac trunk was divided in two vessels, while the third branch originated earlier in the course of the celiac trunk ("false tripod") in $36.4 \%$ of the subjects $(51 / 140)$. In $96.1 \%$ of such "false tripod" cases (49/51), the left gastric artery originated before the hepatic and splenic arteries (hepatosplenic trunk) (Fig. 2). In the remaining 3.9\% of "false tripod" cases $(2 / 51)$, the common hepatic artery arose earlier than the left gastric and splenic arteries (gastrosplenic trunk) (Fig. 3) (Table 1).

Bifurcation of the celiac trunk (type II) was found in $7.1 \%$ of the cadaveric dissections (10/140) (Table 1). The celiac trunk bifurcated into the common hepatic artery and splenic artery (hepatosplenic trunk) in $33.3 \%$ of bifurcations (4/12), whereas the left gastric artery originated from the abdominal aorta (Fig. 4). Bifurcation of the celiac trunk into splenic artery and left gastric artery (splenogastric trunk) artery was found in $25 \%(3 / 12)$, with the common hepatic artery arising from the superior mesenteric artery (Fig. 5). Celiac trunk bifurcation into common hepatic artery and gastric artery (hepatogastric trunk) was observed in $8.3 \%(1 / 12)$, while the splenic artery arose from the SMA (Fig. 6).

Additional branches (type III) were observed in $47.9 \%$ of 


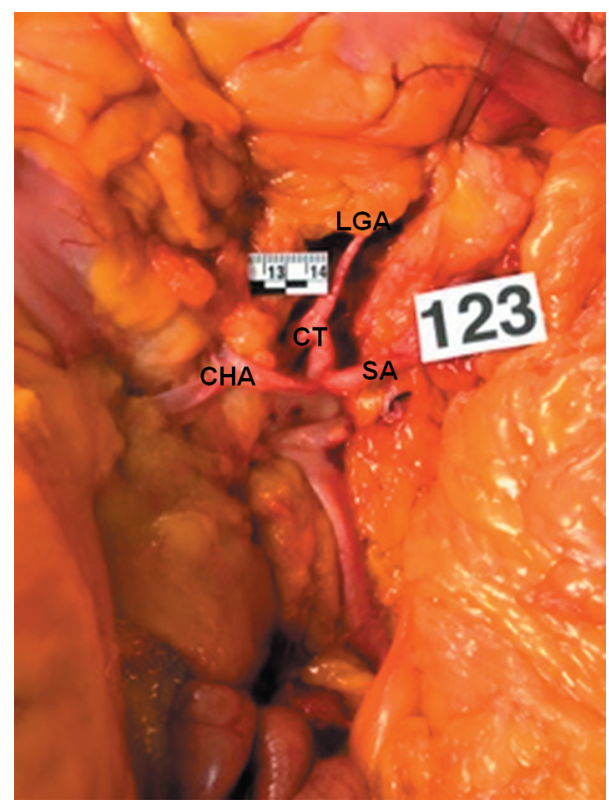

Figure 2. False tripod, the LGA is the first branch of the CT (Panagouli type I, form 2a). AA: abdominal aorta; CT: celiac trunk; LGA: left gastric artery; SA: splenic artery; CHA: common hepatic artery.

the subjects (67/140) (Table 1). Table 2 describes the celiac trunk patterns with additional branches found. One or both phrenic arteries originated from the celiac trunk in $41.4 \%$ of cases (58/140). Separated inferior phrenic arteries originating from the celiac trunk were the most frequent finding $(13.6 \%$, 19/140) (Fig. 7), followed by a right inferior phrenic artery $(10 \%, 14 / 140)$, and both inferior phrenic arteries originating from a common trunk $(7.9 \% ; 11 / 140)$ (Fig. 8). The most common presentation of celiac trunk with additional branches was a false tripod with the left gastric artery arising first, and left and right inferior phrenic arteries arising independently, which was found in $22.4 \%(15 / 67)$, followed by a false tripod, with the left gastric artery arising first, and the right inferior phrenic artery in $17.9 \%(12 / 67)$. Tetrafurcation was found in $32.9 \%$ of the cadavers $(46 / 140)$, while pentafurcation was observed in $12.9 \%(18 / 140)$, hexafurcation in $1.4 \%(2 / 140)$ and heptafurcation in $0.7 \%(1 / 140)$. The first case of hexafurcated celiac trunk was a female cadaver where left and right inferior phrenic arteries arose independently, followed by the left gastric artery and ending in trifurcation into common hepatic artery, splenic artery and dorsal pancreatic artery. The second case of celiac trunk hexafurcation was found in a female cadaver where the left inferior phrenic artery arose first, followed by the left middle adrenal artery, and the right inferior phrenic artery, ending in a common origin for the left gastric, common hepatic and splenic arteries. The case of celiac trunk heptafurcation was a male cadaver where the left inferior phrenic artery arose first, after which the left middle adrenal artery, right inferior phrenic artery and left gastric artery arose independently, and ended in a trifurcation, which gave origin to the common hepatic, splenic and gastroduodenal arteries (Fig. 9).

The mean diameter of the celiac trunk ranged from 6 to $12 \mathrm{~mm}$, with a mean diameter of $7.2 \mathrm{~mm}(\mathrm{SD}=1.39 \mathrm{~mm})$. No

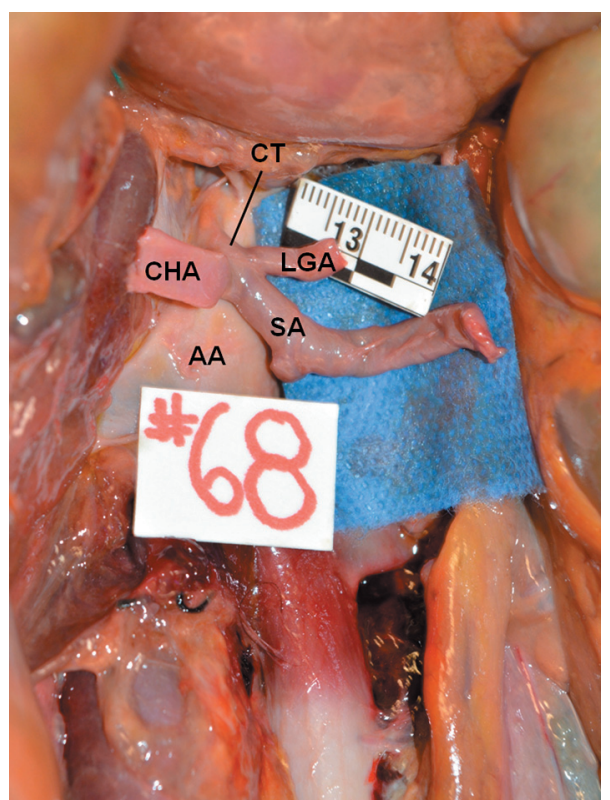

Figure 3. False tripod, the $\mathrm{CHA}$ is the first branch of the $\mathrm{CT}$ (Panagouli type I, form 2b) AA: abdominal aorta; CT: celiac trunk; LGA: left gastric artery; SA: splenic artery; CHA: common hepatic artery.

significant difference was found between the diameters of the different types of celiac trunk ( $\mathrm{P}>0.05)$ (Fig. 10).

The celiac trunk originated in a range between the 10th thoracic vertebral body and the first lumbar vertebral body. The emergence of the celiac trunk was found between the 12th thoracic vertebral body and the first lumbar vertebral body in $90 \%$ of the cadavers, while the median level was at the 12 th thoracic vertebral body (Table 3).

\section{Discussion}

The systematic review by Panagouli et al [8] showed that the celiac trunk trifurcates into the common hepatic artery, the left gastric artery and the splenic artery (type I) in $89.42 \%$ of the cases. The prevalence of this presentation has been found between $40 \%$ and $94.2 \%$ in cadaveric studies, and reaching up to $95.9 \%$ in radiologic studies and $98.3 \%$ in liver transplantation studies [9-12]. Song et al [13] in a radiologic series of 5,002 patients, observed a classic celiac trunk trifurcation in $89.1 \%$ of the patients. Different forms of bifurcated or incomplete celiac trunk (type II) have been found, with prevalence ranging from $1.3 \%$ to $25 \%[3,14]$. The most common types of bifurcation are: hepatosplenic trunk, with the left gastric artery originating from the abdominal aorta $(3.34 \%)$, splenogastric and hepatomesenteric trunk (1.9\%) and splenogastric trunk with the common hepatic artery arising from the superior mesenteric artery $(1.13 \%)$ [8]. The absence of celiac trunk (type VII) is an uncommon presentation, with prevalence ranging from $0 \%$ to $2.6 \%$, with a mean prevalence of $0.38 \%[3,8,14]$.

In our study, celiac trunk trifurcation (type I) was found in $43.6 \%(61 / 140)$, which is a much lower proportion than previously reported. Cadaver, imaging, and liver transplantation 
Table 1. Celiac Trunk Patterns According to the Panagouli Classification in Our Series $(n=140)$

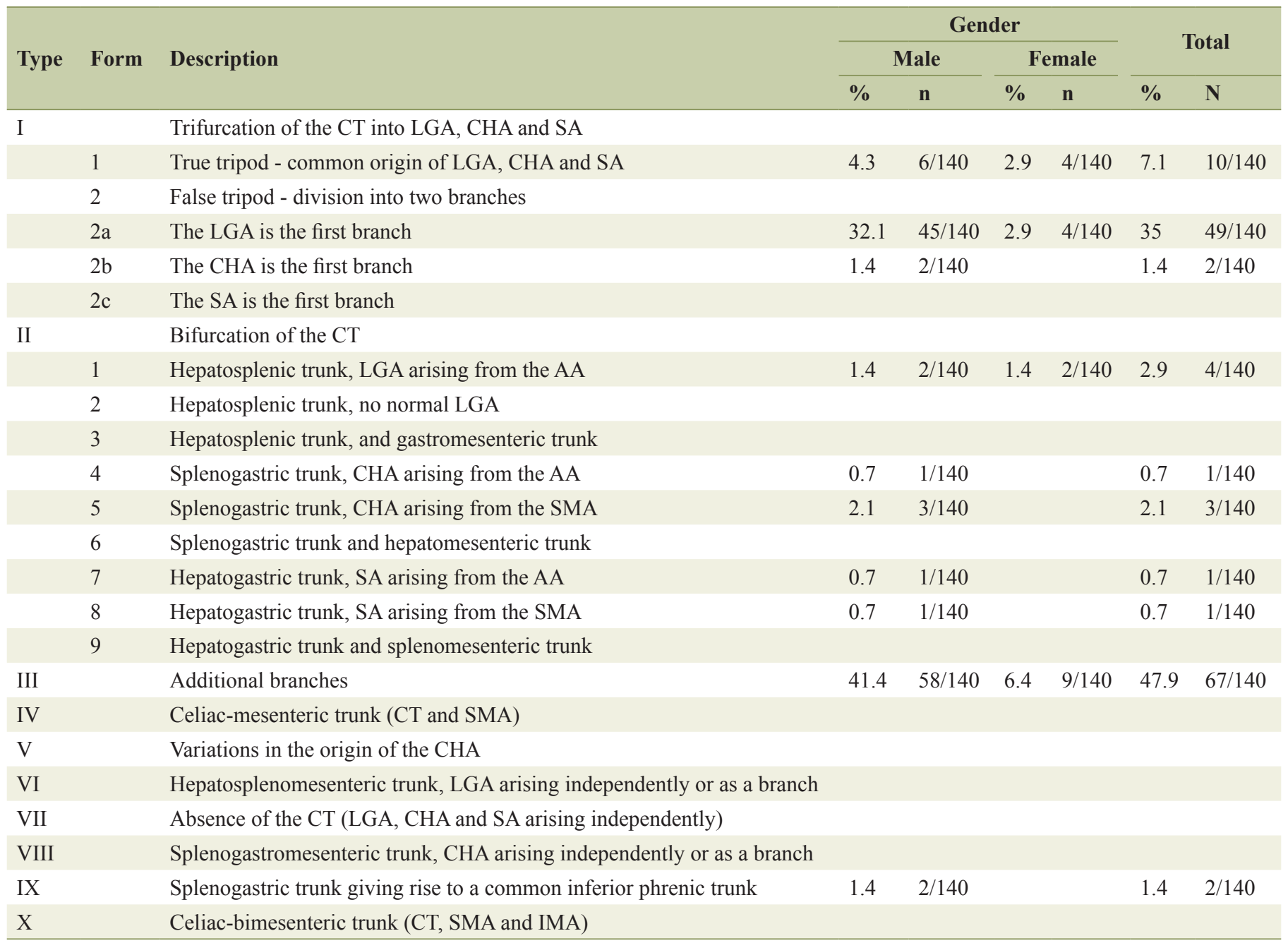

CT: celiac trunk; LGA: left gastric artery; CHA: common hepatic artery; SA: splenic artery; AA: abdominal aorta; SMA: superior mesenteric artery.

studies have reported celiac trunk trifurcation in $85.1 \%, 89.6 \%$, and $95.4 \%$, respectively [8]. In contrast, cadaveric studies by Chitra [9], Nelson et al [15], Mburu et al [16], and Farghadani [17] reported trifurcated celiac trunk prevalences of $40 \%, 60 \%$, $61.8 \%$, and $63.6 \%$, respectively. In our study, the false tripod of the celiac trunk was present in $36.4 \%(51 / 140)$, which predominated over the true form of the celiac trunk $(7.1 \%, 10 / 140)$. The most common form of false tripod was a hepatosplenic trunk, with a left gastric artery as the first branch of the celiac trunk $(35 \%, 49 / 140)$. A gastrosplenic trunk, with a common hepatic artery as the first branch of the celiac trunk was found in $1.4 \%$ $(2 / 140)$. There were no cases of hepatogastric trunk, with the splenic artery as the first branch. A clear predominance of false tripod over true tripod has been reported, with prevalences between $50.4 \%$ and $71 \%$ [7, 18, 19]. Venieratos et al (2013) reported a contrasting predominance of true tripod, with a prevalence of $74 \%$. The most common false tripod is the hepatosplenic trunk, with a left gastric artery emerging first [7]. This is consistent with the findings in our study.

Celiac trunk bifurcation (type II) constitutes the most common variation of the celiac trunk, with a mean prevalence $7 \%$ [8]. In the present series, the prevalence of celiac trunk bifurcation was $7.1 \%(10 / 140)$. The hepatosplenic trunk, with the left gastric artery originating from the abdominal aorta, is the most frequent type of bifurcation $[3,13,16,18,20]$. This is also consistent with the present study $(2.9 \%)$.

Absence of the celiac trunk (type VII) is the most infrequent variation, with a mean prevalence of $0.38 \%$. In many studies, no celiac trunk absence has been found $[3,11,12,15$, $16,20]$. In our study, no case of absence of celiac trunk was found.

Additional branches have been referred by Vandamme et al [21] as collaterals or tributaries. The celiac trunk provides one or more collateral arteries in $50 \%$ of subjects. The most frequent additional branches are single or double inferior phrenic arteries, which have been described in $40 \%$ of cases [22]. In a cadaver study by Greig et al [23], the phrenic arteries originated from the celiac trunk in $46.8 \%$ of the dissections, compared to the abdominal aortic origin, which contributed with $45.1 \%$ of the cases. In $20.9 \%$ of the cadavers, the phrenic 


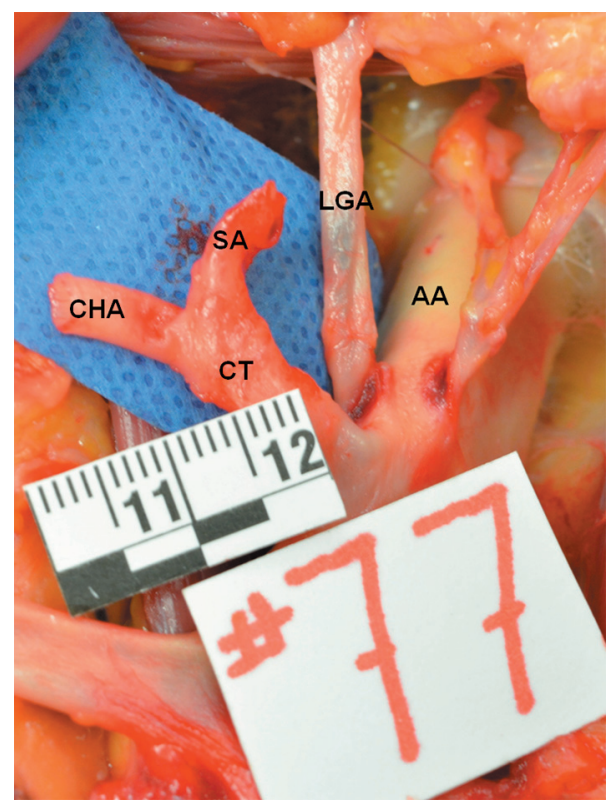

Figure 4. Hepatosplenic trunk, the LGA arises from the AA (Panagouli type II, form 1). AA: abdominal aorta; CT: celiac trunk; LGA: left gastric artery; SA: splenic artery; CHA: common hepatic artery.

arteries arose independently from the celiac trunk, whereas a common phrenic trunk was found in $12.2 \%$ of the specimens. In a multidetector computed tomography study by Basile et al [24] the right and left inferior phrenic arteries arose from the celiac trunk in $41 \%$ and $44 \%$ of the patients, respectively, whereas their origin was from the abdominal aorta in $49 \%$ and $47.5 \%$, respectively. In our series, additional vessels were

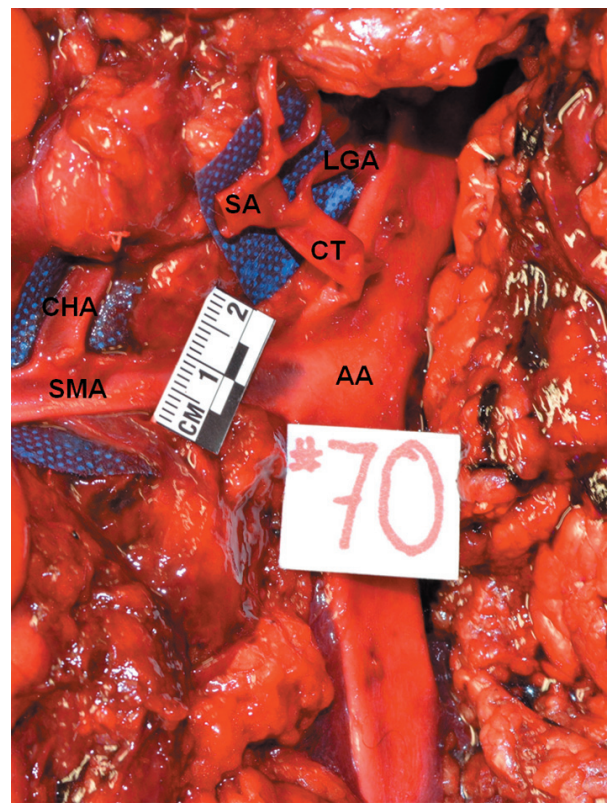

Figure 5. Splenogastric trunk, the CHA arises from the SMA (Panagouli type II, form 5). AA: abdominal aorta; CT: celiac trunk; LGA: left gastric artery; SA: splenic artery; CHA: common hepatic artery; SMA: superior mesenteric artery.

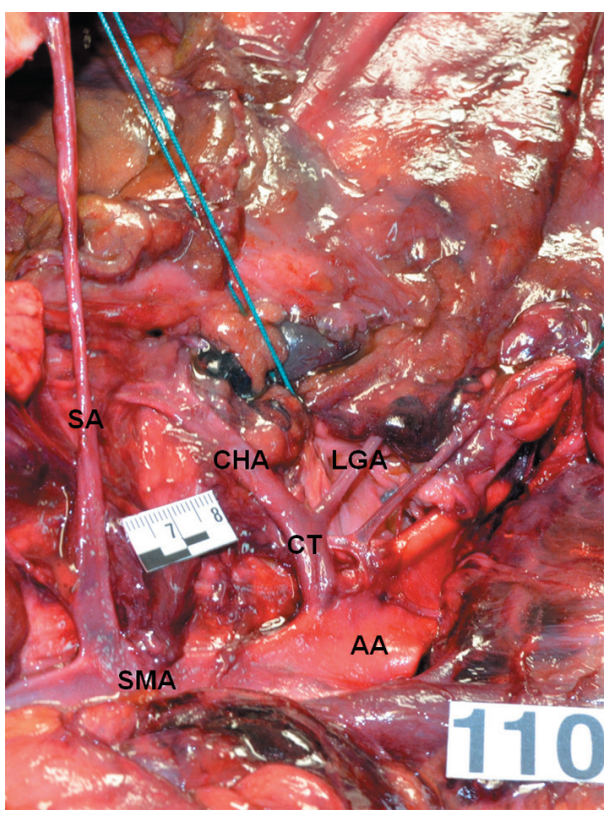

Figure 6. Hepatogastric trunk, the SA arises from the SMA (Panagouli type II, form 8). AA: abdominal aorta; CT: celiac trunk; LGA: left gastric artery; SA: splenic artery; CHA: common hepatic artery; SMA: superior mesenteric artery.

found in $47.9 \%(67 / 140)$ of dissections. One or both phrenic arteries originated from the celiac trunk in $41.4 \%$ of cases $(58 / 140)$. Separated inferior phrenic arteries originating from the celiac trunk were the most frequent finding $(13.6 \%$, $19 / 140)$, followed by a right inferior phrenic artery $(10 \%$, 14/140) (Table 2).

Srivastava et al [25] in a CT-angiographic study found a trifurcated celiac trunk in $28 \%$, bifurcation in $8 \%$, tetrafurcation in $36 \%$, pentafurcation in $20 \%$, and hexafurcation in $4 \%$, while in $4 \%$ the celiac trunk was absent. In our series, $32.9 \%$ of cadavers (46/140) presented a celiac trunk tetrafurcation, while a pentafurcation was found in $12.9 \%$ (18/140), hexafurcation in $1.4 \%(2 / 140)$ and heptafurcation in $0.7 \%(1 / 140)$. Celiac trunk hexafurcation and heptafurcation are uncommon presentations.

Representative reports of celiac trunk hexafurcation are presented in Table 4 [9, 26-29]. Astik and Dave [27] reported a case of celiac trunk heptafurcation, in which a left gastric artery, splenic artery, common hepatic artery, right inferior phrenic artery, gastroduodenal artery, left superior adrenal artery and left middle adrenal artery were observed. In our series, we found one dissection where the left inferior phrenic artery, left middle adrenal artery and right inferior phrenic artery originated prior to the classic three vessels, after which the gastroduodenal artery originated. To our knowledge, our case of celiac trunk heptafurcation is the second reported in literature.

A study by Singh et al [30] observed a mean diameter of the celiac trunk of $6.6 \mathrm{~mm}$, with a minimum $4 \mathrm{~mm}$ and maximum $10 \mathrm{~mm}$. This finding is similar to the mean diameter in our study (7.2 mm, range from 6 to $12 \mathrm{~mm}$ ) (Fig. 10).

The vertebral level of origin of the celiac trunk has been 
Table 2. Celiac Trunk Patterns With Additional Branches (Type III, Panagouli Classification) and Different Forms in Our Series ( $\mathrm{n}=$ 67)

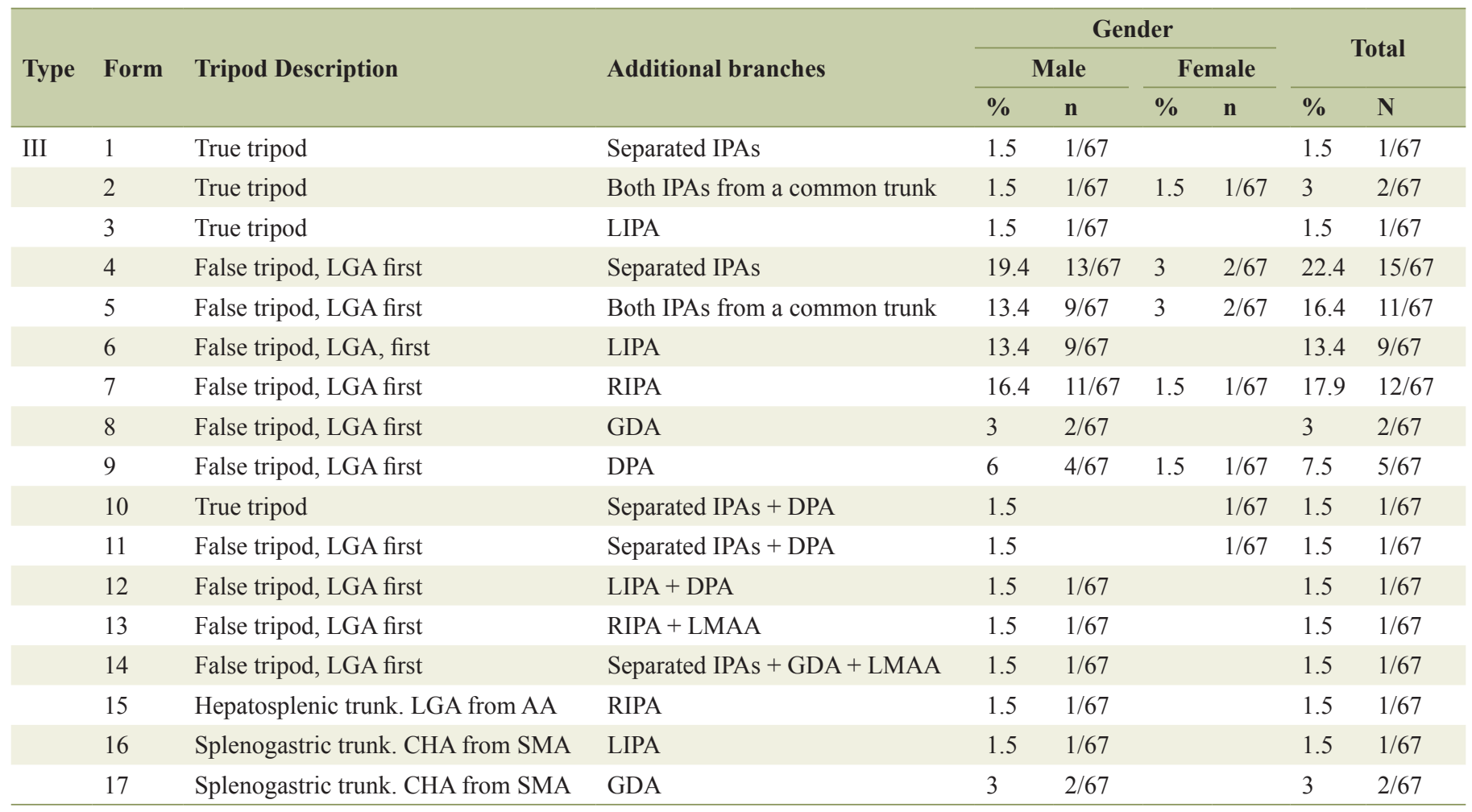

LGA: left gastric artery; CHA: common hepatic artery; AA: aortic artery; IPAs: inferior phrenic arteries; LIPA: left inferior phrenic artery; RIPA: right inferior phrenic artery; GDA: gastroduodenal artery; DPA: dorsal pancreatic artery; LMAA: left medial adrenal artery; SMA: superior mesenteric artery.

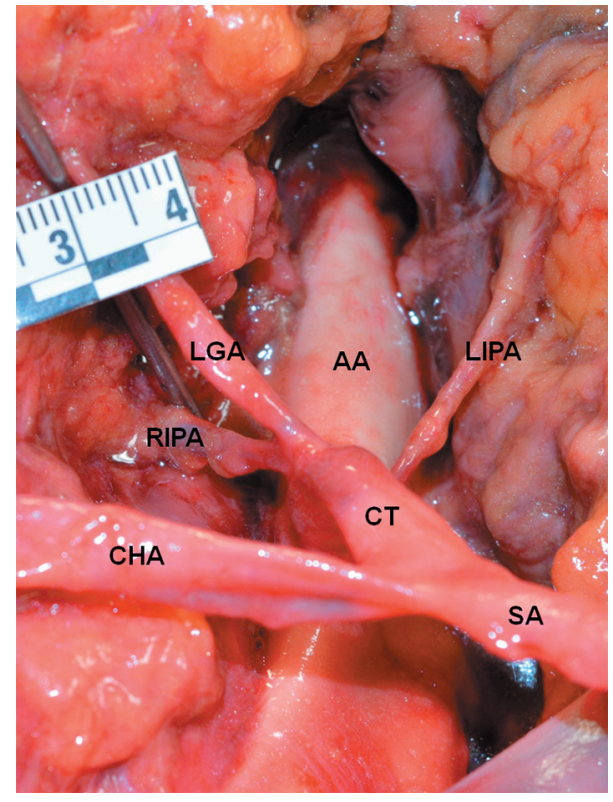

Figure 7. False tripod, the LGA is the first branch of the CT. There are two additional branches, separated RIFA and LIFA (Panagouli type III, form 4). AA: abdominal aorta; CT: celiac trunk; LGA: left gastric artery; SA: splenic artery; CHA: common hepatic artery; RIPA: right inferior phrenic artery; LIPA: left inferior phrenic artery.

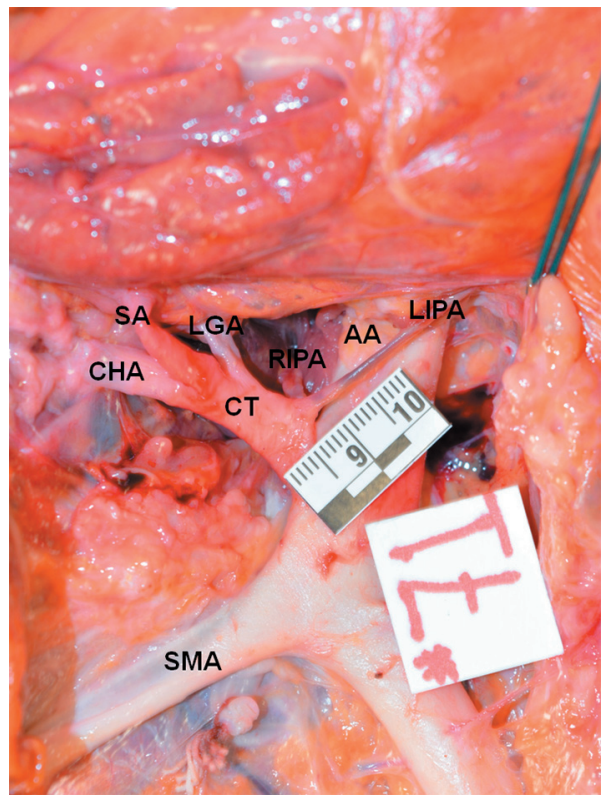

Figure 8. False tripod, the LGA is the first branch of the CT. The RIPA and LIPA arise from a common trunk (Panagouli type III, form 5). AA: abdominal aorta; CT: celiac trunk; LGA: left gastric artery; SA: splenic artery; CHA: common hepatic artery; RIPA: right inferior phrenic artery; LIPA: left inferior phrenic artery; SMA: superior mesenteric artery. 


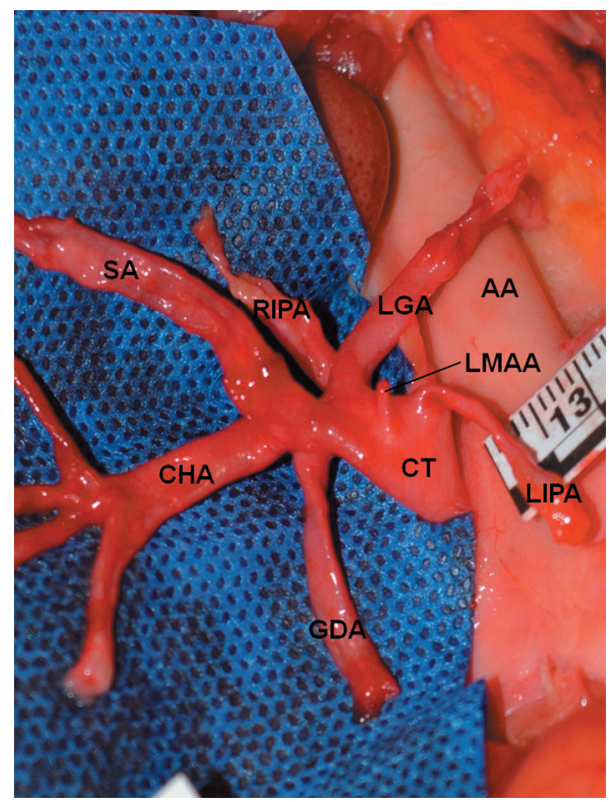

Figure 9. False tripod, the LGA is the first branch of the CT. There are four additional branches, LIPA, LMAA, RIPA and GDA (heptafurcated CT, Panagouli type III form 14). AA: abdominal aorta; CT: celiac trunk; LGA: left gastric artery; SA: splenic artery; CHA: common hepatic artery; LIPA: left inferior phrenic artery; LMAA: left middle adrenal artery; RIPA: right inferior phrenic artery; GDA: gastroduodenal artery.

reported between the 10th thoracic and the second lumbar vertebral body [14, 31-33]. Cauldwell et al [32] reported that almost $75 \%$ of cadaveric dissections showed a celiac trunk origin at a level between the 12th thoracic and first lumbar vertebrae, with a global range between the 11th thoracic and the second lumbar vertebral bodies. In the present study, the celiac trunk originated between the 12 th thoracic vertebral body and the first lumbar vertebral body in $90 \%$ of the cadavers (Table 3 ).
Table 3. Vertebral Level of Origin of the Celiac Trunk in Our Series $(n=140)$

\begin{tabular}{lll}
\hline Vertebral body level & $\mathbf{N}$ & $\mathbf{\%}$ \\
\hline T10 & 1 & 0.7 \\
T10 to T11 & 0 & 0 \\
T11 & 8 & 5.6 \\
T11 to T12 & 5 & 3.6 \\
T12 & 67 & 47.9 \\
T12 to L1 & 19 & 13.6 \\
L1 & 40 & 28.6 \\
\hline
\end{tabular}

T10: 10th vertebral thoracic body; T11: 11th vertebral thoracic body; T12: 12th vertebral thoracic body; L1: first vertebral lumbar body.

Some arteries of small diameter may not be identified in imaging procedures. In liver transplantation and other surgical dissections, the visual appreciation may be limited to the surgical field and some arteries may not be followed in order to identify all their possible ramifications. Cadaveric dissections must identify all the anatomic variations.

The classification proposed by Panagouli et al [8] is based on an extensive review of the literature. All possible variations of the celiac trunk are included. Therefore, our study classified the cadaveric dissection findings according to this classification. We consider it practical and useful. It should be noted that we further classified the type III of such classification, which represents additional branches, in order to classify all the celiac trunk patterns found in our study (Table 2).

The anatomical variants of the celiac trunk are secondary to differences of the embryonic development of the primitive arterial system [34]. A genetic cause has been considered as an explanation to differences in celiac trunk variants. Gender differences are not documented in most studies. Studies by Venieratos et al [14] and Chen et al [20] revealed no differenc-

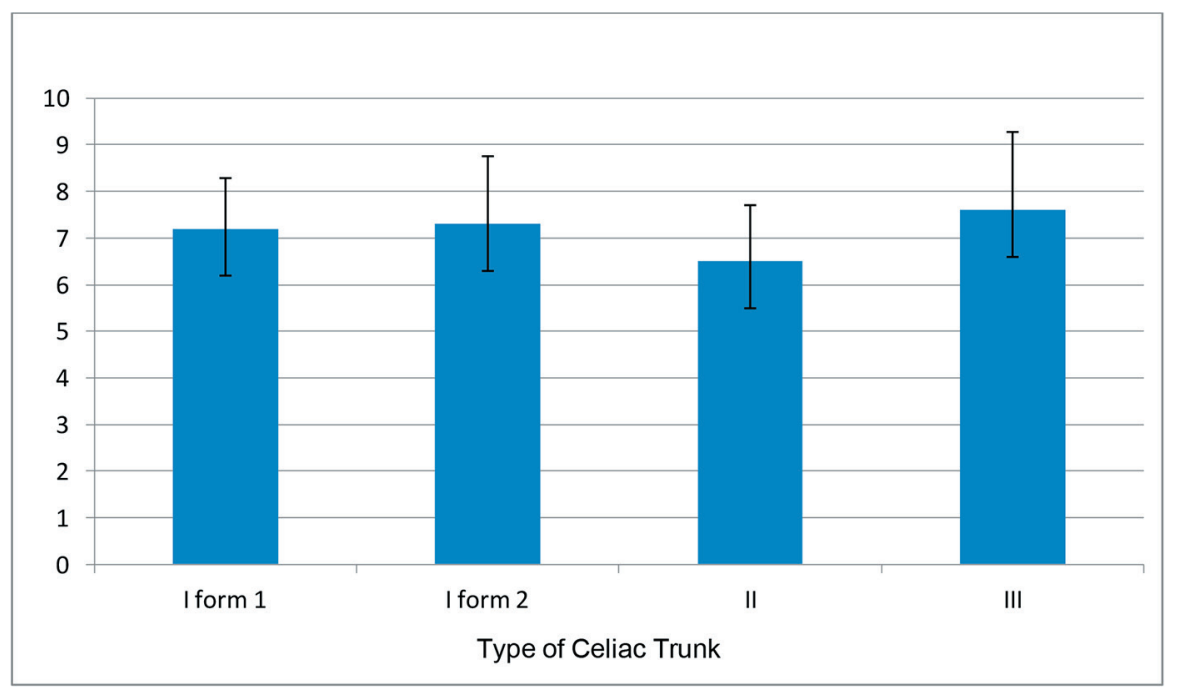

Figure 10. External diameter $(\mathrm{mm})$ of the celiac trunk in the present series $(n=138)$. Data are presented as mean and standard deviation $(P>0.05)$. The two cases of splenogastric trunk giving rise to a common inferior phrenic trunk (Panagouli type IX) are not included. 
Table 4. Description of Celiac Trunk Hexafurcation and Heptafurcation Cases

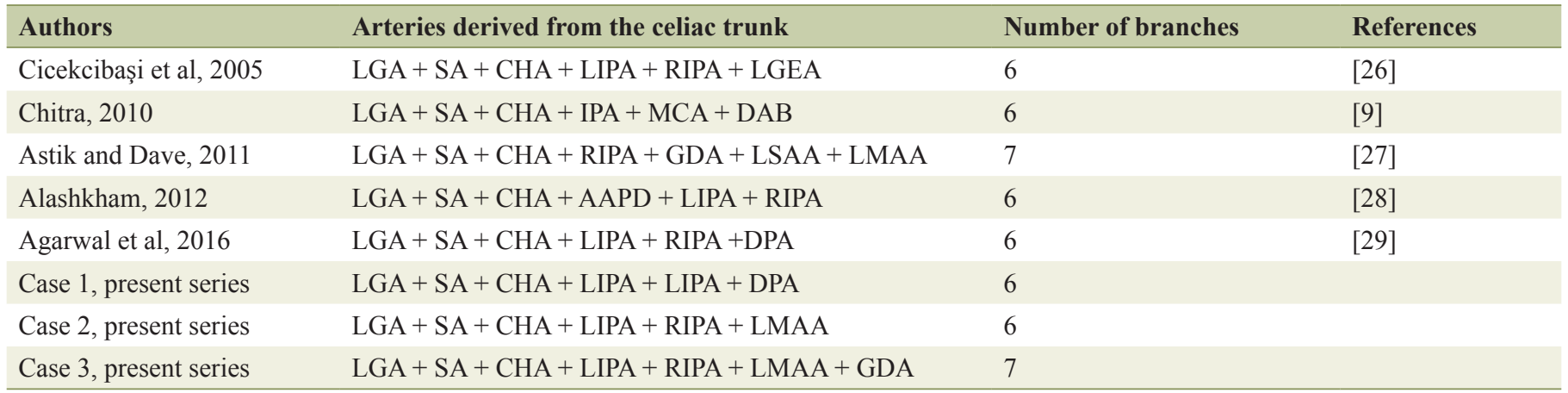

LGA: left gastric artery; SA: splenic artery; CHA: common hepatic artery; LIPA: left inferior phrenic artery; RIPA: right inferior phrenic artery; LGEA: left gastroepiploic artery; GDA: gastroduodenal artery; LSAA: left superior adrenal artery; LMAA: left middle adrenal artery; AAPD: aberrant artery supplying the pancreas and duodenum; IPA: inferior phrenic artery; DAB: duodenal arterial branch.

es between genders. Most dissections in our study were performed in male gender cadavers $(86.4 \%, 121 / 140)$, which limit an appropriate comparison. The incidence of celiac trunk variants may be influenced by ethnicity [8]. Our study was conducted in cadavers of Mexican nationality, and only $43.6 \%$ presented a trifurcated celiac trunk, either a common origin or with one of the three arteries arising first. This incidence is higher than those observed in Korean (10.9\%), Caucasian $(8.6 \%)$, Japanese $(10.7 \%)$, Indian $(30 \%)$ and Afro-American population (39\%) [8]. A study by Araujo Neto et al [35] reported that only $10 \%$ of subjects presented a celiac trunk variation, but ethnicity was not assessed.

Knowledge of the celiac trunk anatomic patterns and variations is clinically relevant for image studies interpretation and image guided interventional procedures, as well as for esophageal, gastroduodenal, hepatic, biliary, pancreatic, splenic and colonic surgical procedures [8, 36, 37].

In conclusion, trifurcation of the celiac trunk was lower than previously reported. A high proportion of cases with additional vessels were found. The inferior phrenic arteries were the most frequent additional branches.

\section{Competing Interests}

The authors declare that have no competing interest

\section{Grant Support}

None.

\section{Financial Disclosure}

None.

\section{References}

1. Pitman AG, Moss D, Stringer MD. 20 Posterior abdomi- nal wall and retroperitoneum. In: Standring S, editor. Gray's Anatomy. The Anatomical Basis of Clinical Practice. 41st ed. Edinburgh: Elsevier. 2015;1083-1097.

2. Haller AV. Icones anatomicae in quibus aliquae partes corporis humani delineatae proponuntur et arteriaum potissimum historia continuter. Gottingen. 1756:Vandenhoeck.

3. Lipshutz B. A Composite study of the coeliac axis artery. Ann Surg. 1917;65(2):159-169.

4. Adachi B. Anatomie der Japaner I. Das Arterien system der Japaner Band II. Kaiserlish-Japanischen Universitat zu Kyoto. Kyoyo: Maruzen Publishing Co. 1928;20-71.

5. Morita M. Reports and conception of three anomalous cases on the area of the celiac trunk and the superior mesenteric arteries. Igaku Kenkyu (Acta Med). 1935;9:159172.

6. Michels NA. Blood supply and anatomy of the upper abdominal organs, with a descriptive atlas. Philadelphia: Lippincott. 1955; 139-143.

7. Higashi N, Shimada H, Simamura E, Hatta T. [Branching patterns of the celiac artery as the hepato-gastro-splenic trunk]. Kaibogaku Zasshi. 2009;84(1):7-10.

8. Panagouli E, Venieratos D, Lolis E, Skandalakis P. Variations in the anatomy of the celiac trunk: A systematic review and clinical implications. Ann Anat. 2013;195(6):501-511.

9. Chitra R. Clinically relevant variations of the coeliac trunk. Singapore Med J. 2010;51(3):216-219.

10. Katsume K, Kanamura E, Sakai K, Yoshizuka M, Hirotsu A, Ishibashi K. Statistics report concerning variations in abdominal visceral arterial supply. Kurume Igaku Zasshi. 1978;41:266-273.

11. Koops A, Wojciechowski B, Broering DC, Adam G, Krupski-Berdien G. Anatomic variations of the hepatic arteries in 604 selective celiac and superior mesenteric angiographies. Surg Radiol Anat. 2004;26(3):239-244.

12. Hiatt JR, Gabbay J, Busuttil RW. Surgical anatomy of the hepatic arteries in 1000 cases. Ann Surg. 1994;220(1):5052.

13. Song SY, Chung JW, Yin YH, Jae HJ, Kim HC, Jeon UB, $\mathrm{Cho} \mathrm{BH}$, et al. Celiac axis and common hepatic artery 
variations in 5002 patients: systematic analysis with spiral CT and DSA. Radiology. 2010;255(1):278-288.

14. Venieratos D, Panagouli E, Lolis E, Tsaraklis A, Skandalakis P. A morphometric study of the celiac trunk and review of the literature. Clin Anat. 2013;26(6):741-750.

15. Nelson TM, Pollak R, Jonasson O, Abcraian H. Anatomic variants of the celiac, superior mesenteric, and inferior mesenteric arteries and their clinical relevance. Clin Anat. 1988;1(2):75-91.

16. Mburu KS, Alexander OJ, Hassan S, Bernard N. Variations in the branching pattern of the celiac trunk in a kenyan population. Int J Morphol. 2010;28(1):199-204.

17. Farghadani M, Momeni M, Hekmatnia A, Momeni F, Baradaran Mahdavi MM. Anatomical variation of celiac axis, superior mesenteric artery, and hepatic artery: Evaluation with multidetector computed tomography angiography. J Res Med Sci. 2016;21:129.

18. Iezzi R, Cotroneo AR, Giancristofaro D, Santoro M, Storto ML. Multidetector-row CT angiographic imaging of the celiac trunk: anatomy and normal variants. Surg Radiol Anat. 2008;30(4):303-310.

19. Petrella S, Rodriguez CF, Sgrott EA, Fernandes GJ, Marques SR, Prates JC. Anatomy and variations of the celiac trunk. Int J Morphol. 2007;25(2):249-257.

20. Chen H, Yano R, Emura S, Shoumura S. Anatomic variation of the celiac trunk with special reference to hepatic artery patterns. Ann Anat. 2009;191(4):399-407.

21. Vandamme JP, Bonte J. The branches of the celiac trunk. Acta Anat (Basel). 1985;122(2):110-114.

22. Loukas M, Hullett J, Wagner T. Clinical anatomy of the inferior phrenic artery. Clin Anat. 2005;18(5):357-365.

23. Greig HW, Anson BJ, Coleman SS. The inferior phrenic artery; types of origin in 850 body-halves and diaphragmatic relationship. Q Bull Northwest Univ Med Sch. 1951;25(4):345-350.

24. Basile A, Tsetis D, Montineri A, Puleo S, Massa Saluzzo C, Runza G, Coppolino F, et al. MDCT anatomic assessment of right inferior phrenic artery origin related to potential supply to hepatocellular carcinoma and its embolization. Cardiovasc Intervent Radiol. 2008;31(2):349-358.

25. Srivastava AK, Sehgal G, Sharma PK, Kumar N, Singh R, Parihar A, Aga P. Various types of branching patterns of celiac trunk. The FASEB Journal. 2012;26(Suppl
1):722.5.

26. Cicekcibasi AE, Uysal, II, Seker M, Tuncer I, Buyukmumcu M, Salbacak A. A rare variation of the coeliac trunk. Ann Anat. 2005;187(4):387-391.

27. Astik RB, Dave UH. Uncommon branching pattern of the celiac trunk: origin of seven branches. Int J Anat Var. 2011;4(1):83-85.

28. Alashkham A. Anomalies of the celiac axis. AXIS. 2012;4(1):1-4

29. Agarwal S, Pangtey B, Vasudeva N. Unusual variation in the branching pattern of the celiac trunk and its embryological and clinical perspective. J Clin Diagn Res. 2016;10(6):AD05-07.

30. Singh BG, Bhatt CR, Patel SV, Mehta CD. Morphometric study of coeliac trunk specific reference to hepatic artery pattern in the west-Indian population. Indian J Surg. 2014;76(5):359-362.

31. Anson B, McVay CB. The topographical positions and the mutual relations of the visceral branches of the abdominal aorta. A study of 100 consecutive cadavers. Anat Rec. 1936;67(1):7-15.

32. Cauldwell EW, Anson BJ. The visceral branches of the abdominal aorta: topographical relationships. Am J Anat. 1943;73(1):27-57.

33. Surucu HS, Oto A, Gokoglu A, Celik HH, Ozdemir B, Be$\operatorname{sim}$ A. Anatomy of the celiac trunk examined by CT imaging of 104 individuals. Morphologie. 2003;87(277):3335 .

34. Tandler J. Uber die varietäten der arteria coeliaca und der en entwickelung. Anat Hefte. 1904;25(2):473-500.

35. Araujo Neto SA, Franca HA, de Mello Junior CF, Silva Neto EJ, Negromonte GR, Duarte CM, Cavalcanti Neto $\mathrm{BF}$, et al. Anatomical variations of the celiac trunk and hepatic arterial system: an analysis using multidetector computed tomography angiography. Radiol Bras. 2015;48(6):358-362.

36. Gielecki J, Zurada A, Sonpal N, Jablonska B. The clinical relevance of coeliac trunk variations. Folia Morphol (Warsz). 2005;64(3):123-129.

37. Noussios G, Dimitriou I, Chatzis I, Katsourakis A. The main anatomic variations of the hepatic artery and their importance in surgical practice: review of the literature. J Clin Med Res. 2017;9(4):248-252. 